\title{
CCA transport in soil from treated- timber posts: pattern dynamics from the local to regional scale
}

\section{Working Paper}

\section{Author(s):}

Clothier, Brent E.; Green, S.R.; Vogeler, I.; Greven, M.M.; Agnew, R.; van den Dijssel, C.W.; Neal, S.; Robinson, B.H.; Davidson, P.

Publication date:

2006-08-02

Permanent link:

https://doi.org/10.3929/ethz-b-000024920

\section{Rights / license:}

Creative Commons Attribution-NonCommercial-ShareAlike 2.5 Generic

Originally published in:

Hydrology and Earth System Sciences Discussions 3(4), https://doi.org/10.5194/hessd-3-2037-2006 
Hydrol. Earth Syst. Sci. Discuss., 3, 2037-2061, 2006 www.hydrol-earth-syst-sci-discuss.net/3/2037/2006/

(C) Author(s) 2006. This work is licensed under a Creative Commons License.
Hydrology and Earth System Sciences Discussions

Papers published in Hydrology and Earth System Sciences Discussions are under open-access review for the journal Hydrology and Earth System Sciences

\section{CCA transport in soil from treated-timber posts: pattern dynamics from the local to regional scale}

B. E. Clothier ${ }^{1}$, S. R. Green ${ }^{1}$, I. Vogeler ${ }^{1}$, M. M. Greven ${ }^{2}$, R. Agnew ${ }^{2}$, C. W. van den Dijssel ${ }^{1}$, S. Neal ${ }^{2}$, B. H. Robinson ${ }^{4}$, and P. Davidson ${ }^{3}$

${ }^{1}$ Sustainable Land Use Team, HortResearch, Private Bag 11-030, Palmerston North, New Zealand

${ }^{2}$ Sustainable Land Use Team, HortResearch, Private Bag 845, Blenheim, New Zealand

${ }^{3}$ Marlborough District Council, Private Bag 443, Blenheim, New Zealand

${ }^{4}$ Institute of Terrestrial Ecology, ETHZ, Grabenstrasse 3, 8952 Schlieren, Switzerland

Received: 15 February 2006 - Accepted: 3 July 2006 - Published: 2 August 2006

Correspondence to: B. E. Clothier (bclothier@ hortresearch.co.nz)

HESSD

3, 2037-2061, 2006

CCA leaching from treated timber posts

B. E. Clothier et al.

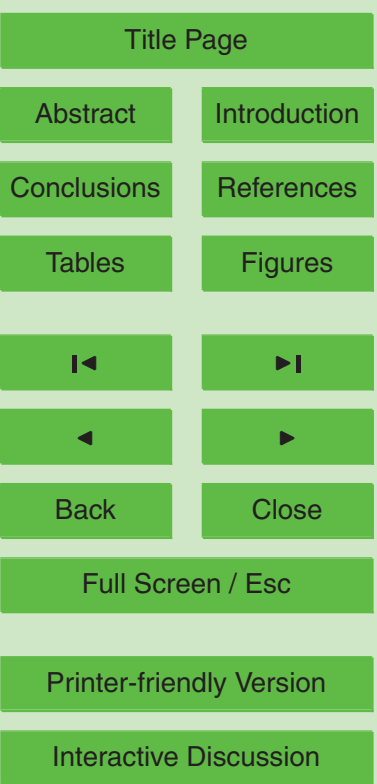




\section{Abstract}

Winegrape growing in many parts of the world, including Marlborough, New Zealand, uses treated-timber posts to act as supports for the grapevine's canopy. At a density of 580 posts per hectare, the $\mathrm{H} 4$-process treated supports result in an areal loading

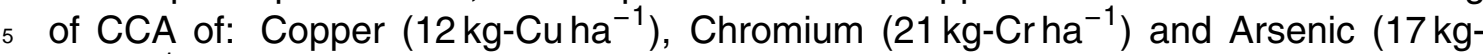
As ha $\left.{ }^{-1}\right)$. Arsenic is the most mobile and toxic of the CCA-treatment cocktail. We describe experiments which indicate that about 4-6 mg-As month ${ }^{-1}$ post $^{-1}$ is released from the subterranean part of the post. We have used SPASMO (Soil Plant Atmosphere System Model) to predict post-to-soil leakage, as well as the pattern dynamics of leach-

ing and exchange around the post. Locally the pattern dynamics of transport and fate are controlled by the soil's chemical characteristics and the prevailing weather. Over its 20-year lifetime, the concentration of arsenic, both that adsorbed on the soil and in the soil solution, exceeds guideline values for soils $\left(100 \mathrm{mg}^{-A s ~ k g}{ }^{-1}\right)$ and drinking water $\left(10 \mu \mathrm{g}-\mathrm{As} \mathrm{L}^{-1}\right)$. Under a regime of $5 \%$ annual replacement of posts, the spatially 15 averaged concentration of arsenic leaching through the soil is predicted to rise to 1.25 to 1.7 times the drinking water standard, depending only slightly on the soil type. The steady value is primarily controlled by the arsenic-release rate from the post. These steady values were used in a simple hydrogeological model of the major Marlborough aquifer systems to determine whether the subterranean flow of water could dilute the descending plumes of arsenic coming from above. Except for the sluggish aquifers of the southern valleys in Marlborough, most of the aquifer systems seem capable of diluting the leachate to between one tenth and one twentieth of the drinking water standard. The upscaling of our modelling of the local pattern dynamics spanned six orders of spatial magnitude, and four orders of time dimension.
HESSD

3, 2037-2061, 2006

CCA leaching from treated timber posts

B. E. Clothier et al.

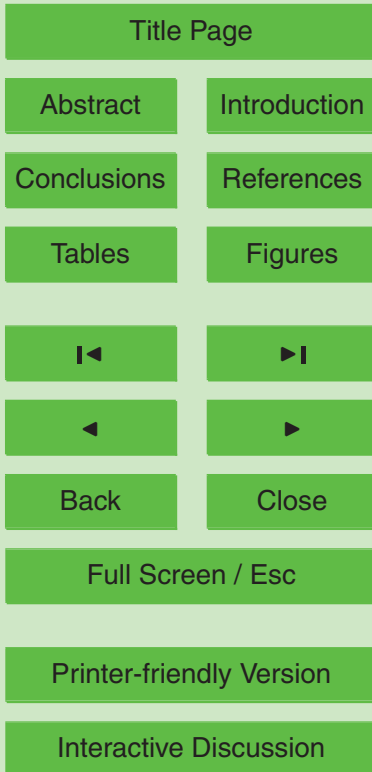




\section{Introduction}

New winegrape-growing regions of New Zealand, Australia, South Africa, Chile and California are characterised by the use of novel viticultural techniques and innovative wine-making procedures, which take full advantage of the unusual terroir of these en-

5 vironments. One characteristic of winegrape growing in many of these regions is the use of chemically treated timber-posts to act as supports for the grape-vine's canopy. At a density of 580 posts per hectare, H4-process treated supports result in an areal loading of CCA of: Copper (12 kg-Cu ha $\left.{ }^{-1}\right)$, Chromium $\left(21 \mathrm{~kg}_{-} \mathrm{Crha}^{-1}\right)$ and Arsenic $\left(17 \mathrm{~kg}-A s ~ h a^{-1}\right)$.

There have been concerns raised in Marlborough, New Zealand, where over 15000 ha of grapes are grown, that the pattern dynamics around the 9 million vineyard posts might have a detrimental impact on the quality of water in the aquifers underlying the Wairau Plains (Bourne, 2003). There are three major aquifer systems in the Wairau Valley, as shown in Fig. 8. The major groundwater system is the trian5 gularly shaped Wairau aquifer, which after about $15 \mathrm{~km}$ meets an aquiclude around Hammerichs' Road. This leads to springs which result in the discharge to surface waters of about $90 \%$ of the groundwater flow. The Rarangi shallow aquifer near the coast, above which there is a burgeoning development of vineyards, discharges into the sea of Cloudy Bay. Flowing north into Wairau Valley are the aquifers of the southern valleys of the Brancott, Omaka, and the Fairhall. All these aquifer systems are a prime source of potable water and irrigation. Furthermore the former two discharge into sensitive receiving waters.

It is therefore critical that the pattern dynamics of local-scale leaching around these CCA-treated posts in vineyards does not, in spatial and temporal sum, compromise 25 the quality of water in the underlying aquifers. In a previous paper (Robinson et al., 2006), we described the results of a general survey of the soil immediately around posts of various ages across a range of soil types. Very close to the posts, within $50 \mathrm{~mm}$, we found that about $25 \%$ of our soil samples exceeded the guideline values
HESSD

3, 2037-2061, 2006

CCA leaching from treated timber posts

B. E. Clothier et al.

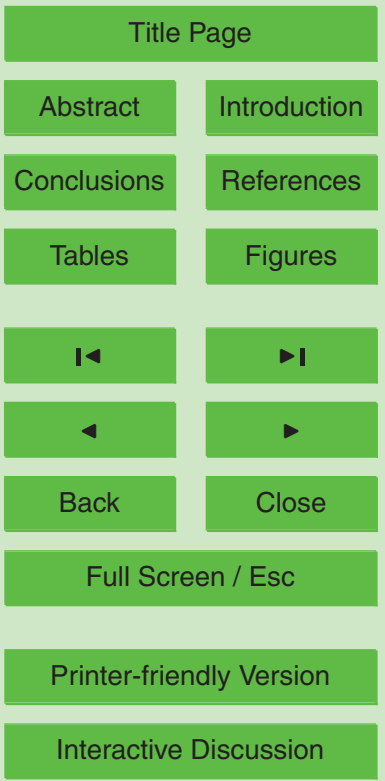

EGU 
for arsenic in Australia's National Environmental Protection Measures (NEPM, 1999). Some $10 \%$ of our samples exceeded guideline values for chromium (Cr). Obviously, CCA is leaching from the post into the receiving environment of the soil. Now, our goal here is to assess the risk that the pattern dynamics of CCA, in particular the 5 most mobile and toxic arsenic, might lead to leaching into the underlying aquifers and degrade the groundwater.

The local regulatory agency, the Marlborough District Council, first sought an understanding of the long-term impact of the use of CCA-treated posts on the soil immediately surrounding the posts, say within $50 \mathrm{~mm}$ of the post, across the range of soils 10 found in the Wairau Valley. Further, they wished to understand the underlying impact of these posts, at a density of $580 \mathrm{ha}^{-1}$, on their major aquifers. These aquifers range in spatial extent from $10-75 \mathrm{~km}^{2}$. They sought long-term predictions, over 500 years, of the use of treated posts. In addition, we needed to incorporate sequences of post replacement, for on average, each post is replaced every 20 years.

15 To realise spatial and temporal predictions that would be useful for the Council, we needed to understand the pattern dynamics of arsenic leakage and leaching at the local scale around the post under different As-soil exchange conditions. As well, we needed to determine the pattern dynamics of transport and flow at the spatial scale of the vineyard and landscape over several centuries.

In this paper we describe our measurement and modelling of the pattern dynamics of arsenic leakage and leaching at the local scale surrounding the post. Here it is likely that the "chemistry" dominates. Next, we outline how we upscaled these findings to model leaching at the landscape scale of assemblages of vineyards above the key aquifers. Here the pattern dynamics are probably dominated by the source strength of arsenic, and the "physics" of the flow system. Our study focuses mainly on arsenic, as this is the most mobile and toxic of the CCA-treatment cocktail.

We describe the SPASMO (Soil Plant Atmosphere System Model) scheme that we used to predict the post-to-soil leakage, leaching and soil exchange. We outline the parameterisations used in SPASMO, and then we describe the application of the scheme

HESSD

3, 2037-2061, 2006

CCA leaching from treated timber posts

B. E. Clothier et al.

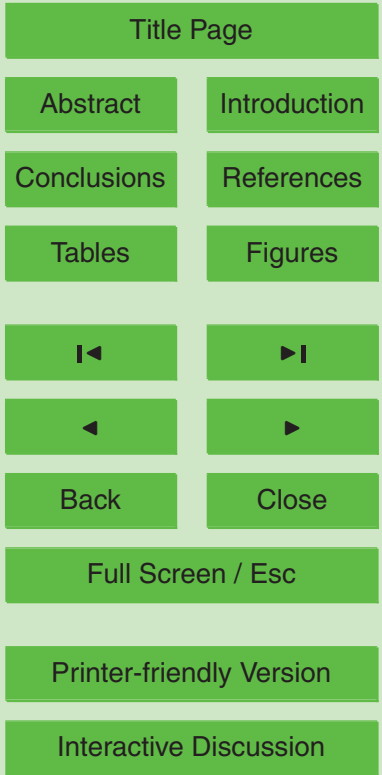

EGU 
to predict the build-up around the post and leaching under it, over the time scale of a single post's life in the soil, namely 20-30 years. These predictions are compared with the results from our general survey (Robinson et al., 2006). We then discuss our predictions of the impact of sequential post replacement every 20 years, over a period of

5500 years. The predictions of the pattern dynamics from this modelling are then used in a simple mass-balance model of the hydrogeology of the key aquifers to predict the exit concentration of arsenic at the distal interface of the subterranean system. This exit interface is either where it rises to feed surface waters, or where the subterranean flow enters the sea, or another aquifer system. Our analyses of the pattern dynamics 10 transcends many spatial scales: spatially - from the $\mathrm{mm}$ scale around the post, to the $\mathrm{km}$ scale of aquifers (six orders of magnitude); and temporally - from the daily scale to that of half a millennium (four orders of magnitude).

\section{SPASMO modelling}

Our mechanistic transport and fate model, SPASMO, (Green et al., 2002; Rosen et al., 15 2004), was modified to describe the series of processes that control: the rate of chemical release from the post to the soil solution, the equilibrium partitioning of chemical between adsorbed and aqueous phases in the soil, and the downward movement of dissolved arsenic through the soil profile. The SPASMO modelling approach predicts the temporal evolution of each process. Parameters for the modelling were taken from data collected during laboratory studies on a range of Marlborough soils, and from lysimeter studies using vineyard posts submerged in water.

Water and chemical movement through the soil is modelled by considering a 1dimensional soil profile $5 \mathrm{~m}$ deep, which is divided into $0.1 \mathrm{~m}$ intervals, or slabs. The calculations were run with a daily time-step, and they consider the water balance to be that of a bare soil, for that is what immediately surrounds the post. A standard crop-factor approach was used to relate the soil evaporation to the prevailing weather (Allen et al., 1999). Water movement through the soil profile was calculated using a

HESSD

3, 2037-2061, 2006

CCA leaching from treated timber posts

B. E. Clothier et al.

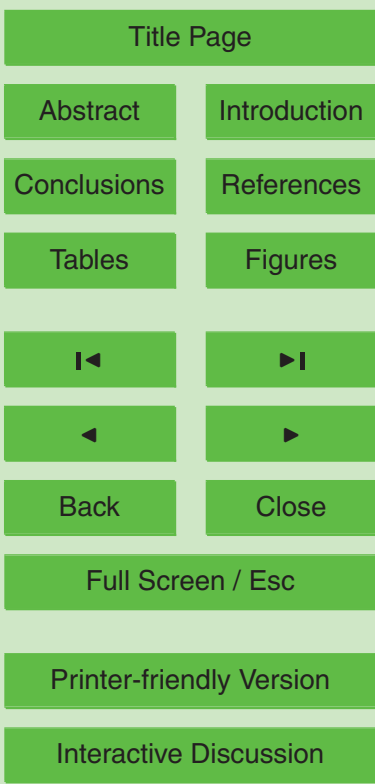

EGU 
water-capacity approach (Hutson and Wagenet, 1993) that considers the soil to have both mobile and immobile pathways for water and chemical transport. The mobile domain represents the soil's connected macropores (e.g. old root channels, worm holes and cracks), with the immobile domain being the micropores of the soil's matrix. After 5 rainfall or irrigation, any dissolved chemical is allowed to percolate rapidly through the soil in the mobile domain only. Subsequently, on days when there is no significant rainfall, there is a slow approach to equilibrium between the mobile and immobile phases, driven by a difference in water content between the two domains.

Once the chemical enters the soil, it is partitioned into either the liquid $\left(\mathrm{mg} \mathrm{L}^{-1}\right)$, 10 or adsorbed phase $\left(\mathrm{mg} \mathrm{kg}^{-1}\right)$. Chemical mobility and its propensity to leach depend on how the chemical is partitioned. Any chemical adsorbed onto the soil particles will not leach. For modelling purposes, we assume a linear equilibrium partitioning between the solution and adsorbed phases. The adsorbed-liquid partitioning is expressed through the isotherm:

${ }_{15} C_{S}=K_{D} C_{L}$

where $C_{S}$ is the adsorbed concentration [mg-As kg${ }^{-1}$ ], $C_{L}$ is the solution concentration [mg-As $\left.\mathrm{L}^{-1}\right]$, and $K_{D}\left[\mathrm{~L} \mathrm{~kg}^{-1}\right]$ is the distribution coefficient. We assume here for simplicity that the isotherm is linear, even though it has been shown that as concentration rises the adsorption curve flattens (Islam et al., 2003). At our somewhat low values of arsenic in the soil solution, a linear isotherm is nonetheless reasonable. Our particular $K_{D}$ values were taken from measurements of arsenic exchange using just the $2 \mathrm{~mm}$ sieved fraction of the soil. The adsorption isotherms for arsenic, which provided the distribution factor, $\mathrm{K}_{D}$, were measured, using batch methods, by the Institute of Natural Resources at Massey University, Palmerston North, New Zealand. These results were extrapolated by incorporating the fraction greater than $2 \mathrm{~mm}$, and also by accounting for the varying organic-carbon fractions using a $k_{o c}$ approach. This general approach is broadly supported by the findings of Goldberg et al. (2005) and Islam et al. (2003), who noted the link between arsenic adsorption and organic carbon (C) content. The

HESSD

3, 2037-2061, 2006

CCA leaching from treated timber posts

B. E. Clothier et al.

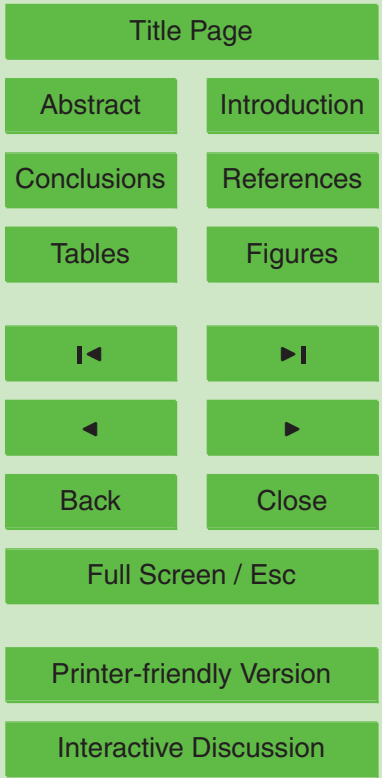

EGU 
total carbon content (TC) was measured with a Leco furnace (Laboratory Equipment Corporation), St Joseph, Michigan, USA) by Landcare Research, Palmerston North. Other land management factors could, nonetheless, have an impact on arsenic leaching, for as Álvarez-Benedi et al. (2005) and Smith et al. (2002) found, phosphates, 5 through competition for exchange sites, decreased the adsorption of arsenic, whereas nitrate had the opposite effect. We have not considered this. The detailed analytical results can be found in our report to the Marlborough District Council (Vogeler et al., 2005). Here, we concentrate on our predictions of the spatial-pattern dynamics of the arsenic fluxes at the local and regional scales, over temporal scales from daily through 10 to 500 years.

We consider the case of a single, H4-treated, full-round post of radius $75 \mathrm{~mm}$, rammed into a bare vineyard soil. The post is considered buried to depth $d_{p}=0.6 \mathrm{~m}$. Chemical release is modelled as a buried source with $1 / 3$ of the chemical being released through the side face, and the remaining $2 / 3$ being released through the post

end. This fraction is consistent with the end-grain diffusivity being 40 times greater than the face-grain (Brookes, 2005). Total chemical release through the outer surfaces of the buried post into soil $Q_{i}^{s}\left[\mu \mathrm{g}(\mathrm{CCA}\right.$ species $\left.i) \mathrm{m}^{-2} \mathrm{~d}^{-1}\right]$ is calculated by modifying the loss we could measure by submerging posts in water, $Q_{i}^{w}$. We assume all leaching into the soil occurs from the subterranean part of the post only. The loss rate from the post 20 into the soil-water solution we take as being that we could measure into water alone, multiplied by the volume fraction of water in the soil at saturation, $\theta_{s}$, so

$Q_{i}^{s}=\theta_{s} Q_{i}^{w}$

This assumption provides a worse-case scenario, for the soil will often be at water contents less than saturation; $\theta \leq \theta_{s}$. However, this saturated assumption would be parts of the post, especially the end-grain. Also, we limit lateral chemical movement to within $50 \mathrm{~mm}$ of the post, and carry out our hydraulic modelling, to depth, within this annular cylinder (Fig. 1).

\section{HESSD}

3, 2037-2061, 2006

CCA leaching from treated timber posts

B. E. Clothier et al.

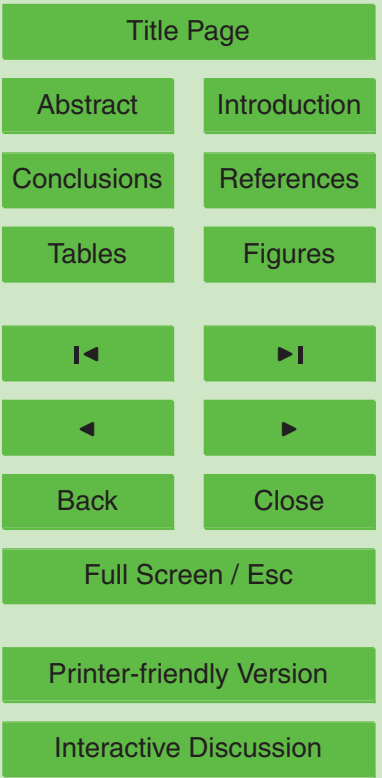

EGU 
Model calculations were first run on a daily time-step using a 32-year sequence of weather data (1972-2004) recorded from the Marlborough Research Centre. These data were obtained from the National Institute of Water and Atmosphere's (NIWA) climate database using the on-line search engine "METSEEK" developed by HortRe5 search. The soil physical and hydraulic properties were deduced from data contained in the NZ Soils Database of Landcare Research, or by using our own measurements made earlier at Rarangi.

\section{Post-to-Soil leakage, exchange and leaching}

Fixation of CCA in treated wood is a complex process. The metals are strongly bound 10 by a number of mechanisms, including ion exchange and hydrogen bonding (Jin and Archer, 1991). Conversely, how the chemical then leaves the wood, and how quickly these losses will occur are both governed by complex processes. The literature contains conflicting reports regarding release rates of CCA from treated posts, partly because of the different ratios of face to end-grain in the samples being studied (Brookes, 2005). In our quest, the first critical step in modelling the leaching risk to groundwater was to get the correct rate of chemical release from the posts. Here we used data where full-round posts (three replicates) had been submerged in freshwater. Water samples were collected at one-month intervals to assess the release rate from the posts. Data from these submerged posts are used here to determine the rate of release of CCA species $i$ through the surfaces of the post into the water, $Q_{i}^{w}[\mu \mathrm{g}$ (CCA species $i) \mathrm{m}^{-2} \mathrm{~d}^{-1}$ ]. Figure 2 shows the rise in the concentration of the three CCA species in the container containing full-round posts.

Chemical leaching from the posts submerged in water, can, we consider, be described using a first-order rate equation of the form

${ }_{25} Q_{i}^{w}=\left[\frac{1}{S_{A}}\right] \frac{d P_{i}}{d t}=k_{1}^{i} P_{i}$

\section{HESSD}

3, 2037-2061, 2006

CCA leaching from treated timber posts

B. E. Clothier et al.

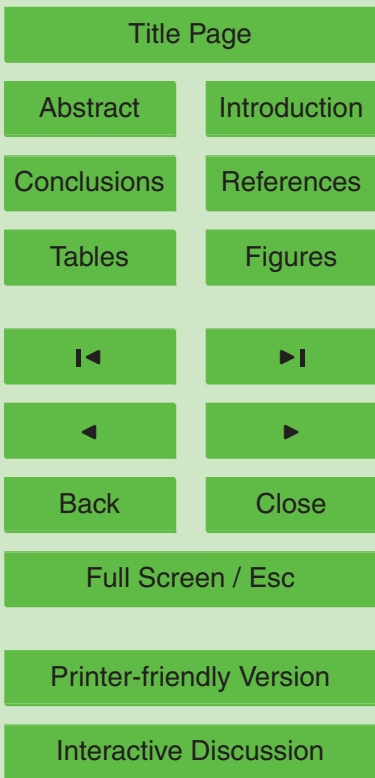

EGU 
where $Q_{i}^{w}\left(\mu \mathrm{g} \mathrm{m}^{-2} \mathrm{~d}^{-1}\right)$ is the release rate of species $i$ into the water, $P_{i}[\mu \mathrm{g}]$ is the total chemical content in the post, and $k_{1}^{i}$ is a "constant" we determined from the rise in solution concentration over time (Fig. 2). The parameterisation of $k_{1}^{i}$ was achieved using a linear fit to the concentration-rise data, assuming that the submerged area $S_{A}\left(\mathrm{~m}^{2}\right)$ 5 includes both cylindrical face and end-grain areas. Our values of $k_{1}^{i}$ for $\mathrm{Cu}, \mathrm{Cr}$ and As were $0.019( \pm 0.003), 0.068( \pm 0.011)$ and $0.055( \pm 0.013)$, which suggest that about $2 \%, 7 \%$ and $5 \%$ of the post's resident CCA is released annually. The concentration data collected in our lysimeters (Fig. 2) confirm that chemical release of CCA is ranked as $\mathrm{Cr}>\mathrm{Cu}>\mathrm{As}$, reflecting the different resident concentrations, as well as the varying 10 release rates. Unfortunately, arsenic is, however, the most toxic and mobile of the CCA species.

Model predictions of the rise in the soil's arsenic concentration some $50 \mathrm{~mm}$ under the post are shown (Fig. 3) for three soil types typical of the Marlborough region: the Woodbourne, Rarangi and Spring Creek series. In the heavier and more-adsorptive 15 soils of the Woodbourne series, over the lifetime of the post, the concentration in the

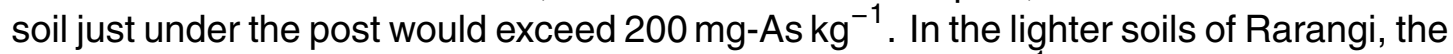
arsenic concentration would not quite exceed $100 \mathrm{mg}^{-} \mathrm{As} \mathrm{kg}^{-1}$ over the post's lifetime. The Spring Creek soils are intermediate to the other two. The NEPM guideline level for arsenic in agricultural soils has been set at $100 \mathrm{mg} \mathrm{kg}^{-1}$ (National Environmental 20 Protection Measures, 1999). Our calculations suggest this value could be reached on the heavier soils after just 10 years (Fig. 3). However, it is worth noting that the actual zone into which the arsenic is released represents just $0.05 \%$ of the vineyard surface area, given that the spatial density of posts, $\rho$, is $580 \mathrm{ha}^{-1}$. We consider that the flux and adsorption of arsenic is contained within a $50 \mathrm{~mm}$ annular cylinder of the post.

25 We are encouraged by the fact that the predicted pattern dynamics are broadly similar to the general survey data reported by Robinson et al. (2006) who sampled soil around many vineyard posts of varying ages on many soils (Fig. 3). This comparison is across a broad range of soils and location, and the measured variation is naturally

HESSD

3, 2037-2061, 2006

CCA leaching from treated timber posts

B. E. Clothier et al.

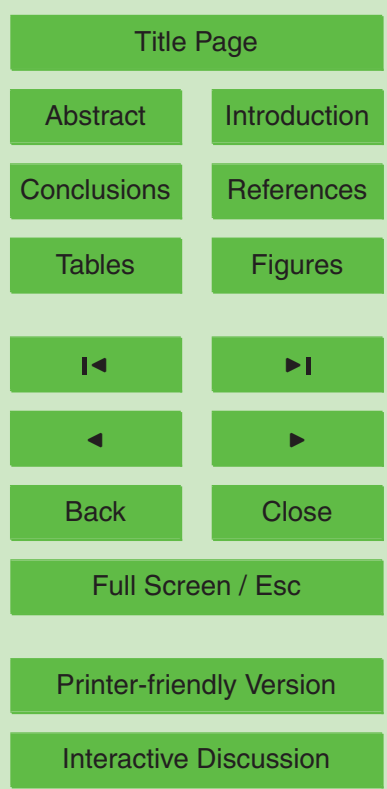

EGU 
large. Nonetheless, the similarity of these general survey results with our simulation modelling is heartening. So the model output seems to have been generally verified, as the data are of a similar magnitude, and show an accumulation over time. We would not expect an exact match between those measurements and our modelling, not only 5 because of simplifications in our modelling, but also because of the natural variability in the general survey measurements.

\section{Spatial-pattern dynamics over the lifetime of a post}

For the soil at Rarangi, we show in Fig. 4 the pattern of penetration of the flux of arsenic, $m(z)$ [mg-As post ${ }^{-1}$ month $^{-1}$ ], at the depths of $z=1,2$ and $3 \mathrm{~m}$. Also shown in Fig. 4 10 is the gradual decline in the integrated flux of arsenic quitting the subterranean portion of the post. We predict this source strength of arsenic using a surface integration of Eq. (3) in our SPASMO scheme. The loss of arsenic from the post drops from just under $6 \mathrm{mg} \mathrm{month}^{-1}$, to around about 4.5 over the 30 -year period. The depthwise penetration of the As plume under the post, through a circle of radius $125 \mathrm{~mm}$ (Fig. 1), shows that 15 in this soil of low As-adsorptive capacity, there are high flux densities, and there is only a moderate diminution of the flux with depth. Our simulations on the other soils, reported by Vogeler et al. (2005) revealed the strong influence of the soil's chemical characteristics on the spatial pattern of fluxes, and adsorption. In Fig. 4 can also be seen the strong influence of daily and seasonal weather patterns

\section{Temporal-pattern dynamics over 500 years}

To predict the long-term pattern dynamics of As, we then carried out SPASMO modelling over 500 years. To do this, we used in the model sequentially, the same 32-year weather record. We considered first, the transport and fate from a single post sitting in the soil for the entire 500-year period. Then we modelled the system dynamics with an
HESSD

3, 2037-2061, 2006

CCA leaching from treated timber posts

B. E. Clothier et al.

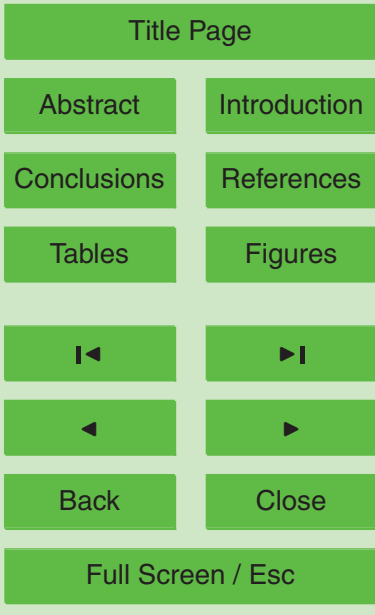

Printer-friendly Version

Interactive Discussion 
annual rate of post replacement of $5 \%$. This means that, on average, any given post is replaced after 20 years, and a 'fresh' one installed in the same hole. Thus the leaching process begins anew, some 25 times during the 500-year simulation. In presenting the results from these long-term simulations, for ease of graphing we have only plotted the 5 values for the 1 st of every month.

Figure 5 shows the long-term trend in dissolved arsenic in soil close to, and alongside a CCA-treated timber post in the heavier Woodbourne soil. In the case of a single permanent post, the arsenic concentration locally in the soil solution reaches a peak of just under $4 \mathrm{mg} / \mathrm{L}$ after about 100 years. Thereafter the solution concentration declines 10 because less arsenic is released from the ageing post. Next, we modelled the replacement scenario by assuming a "fresh" post is placed back into the same hole in the soil every 20 years. In this case, it takes about 300 years for the dissolved concentration to reach a steady concentration of about $8 \mathrm{mg}_{-} A \mathrm{sL}^{-1}$. This is over twice the peak solution-concentration for soil around a single, permanent timber post. Now the pattern 15 dynamics of the replacement scenario is dominated by the source strength of arsenic over the post's lifetime. This is about $5 \mathrm{mg}^{-A s}$ post $^{-1}$ month $^{-1}$ (Fig. 4). After 300 years, the soil's adsorptive capacity surrounding the post would become quenched, and there would be little impact of the soil's chemistry on the pattern dynamics of the flux, rather it would be dominated by the transport "physics", and primarily by the source strength of arsenic as a result of the cycles of post replacement.

Next, these flux patterns, under a replacement regime, were upscaled to a unit area of vineyard by considering there to be 580 posts ha ${ }^{-1}$, and spatially averaging the flux by noting that the arsenic plumes within the $50 \mathrm{~m}$ cylinders surrounding each post only represent $0.05 \%$ of the vineyard area. From this spatially averaged flux, since the flow of water was also predicted by our model, we could predict the spatially averaged concentration of arsenic that would be in the solution $\left(\mathrm{mg}-\mathrm{As} \mathrm{L}^{-1}\right)$ leaching through the soil.

For three soil types shown in Fig. 6, we present the spatially averaged solution concentration of As at the depths of 1 and $2 \mathrm{~m}$. In the highly permeable soil of Rarangi, the
HESSD

3, 2037-2061, 2006

CCA leaching from treated timber posts

B. E. Clothier et al.

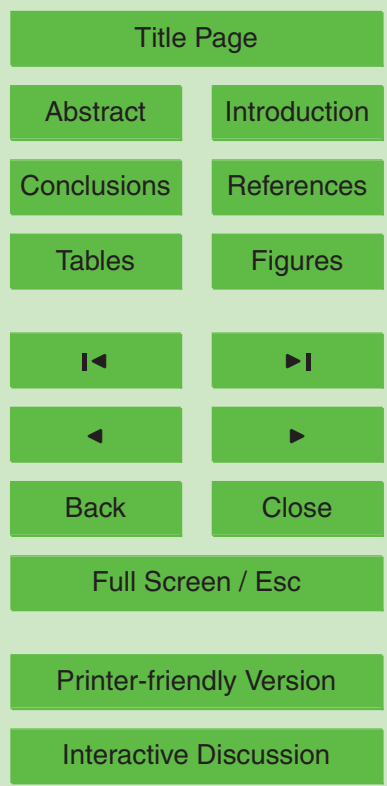

EGU 
signal is very spiky, in part because we have only plotted monthly values, but in greater part because of the high hydraulic conductivity of the soil, and low saturated water content of the soil. The pattern dynamics reflect the intermittent nature of the rainfall events which lead to drainage. As noted, the "physics" of the flow system, and the 5 source strength of As in the posts dominates in the long-term, and the steady concentration is similar across all soil types. In all cases, the steady value is about 1.25 to 1.7 times the New Zealand Drinking Water Standard NZDWS (Ministry of Health, 2000) of $10 \mu \mathrm{g}-\mathrm{As} \mathrm{L}^{-1}$. Nonetheless, the 'chemistry' affects the time taken to reach steady state. This would be achieved in the low adsorptive soil of Rarangi after about 80-100 years, 10 whereas it would take some 300 years to realise this for the Woodbourne and Spring Creek soils.

Because these values of the spatially averaged leachate concentration exceed the drinking water standard, unless the groundwater dynamics are such that sufficient lateral subterranean flows can dilute and flush the As-leachate arriving from above, then there are prospects for groundwater degradation through an eventual build-up of As.

Next, therefore, we carried out simple hydrogeological modelling of the major Marlborough aquifer systems to assess whether the descending As plume might possibly be diluted by lateral flow in the aquifer.

\section{Hydrogeological modelling of the dynamics in aquifer systems}

20 A simple mass-balance model of the hydrogeology was developed to predict the likely long-term concentration of arsenic in the groundwater systems of the plains. Our simple rectangular-slab model of an aquifer is presented in Fig. 7. This aquifer is of thickness $D[\mathrm{~m}]$, and has its phreatic surface some distance below the soil surface, and it is considered to have water travelling at pore velocity $v$ [m day ${ }^{-1}$ ] along its length $L_{1}$ $25(\mathrm{~km})$. The aquifer is of width $L_{2}(\mathrm{~km})$ and has porosity $\Theta$. The arsenic loading from the

\section{HESSD}

3, 2037-2061, 2006

CCA leaching from treated timber posts

B. E. Clothier et al.

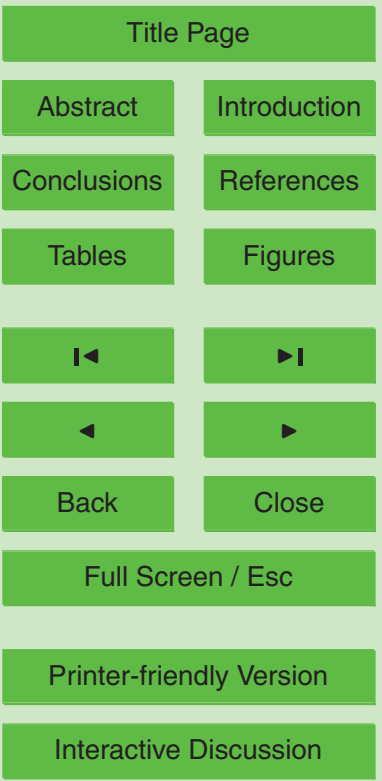

EGU 
posts above is taken as $T\left(\mathrm{mg}^{-A s} \mathrm{yr}^{-1}\right)$, which can be found from

$T=m \rho L_{1} L_{2}$

where $m$ is the average flux density of As release from the post over its 20-year life [mg-As post ${ }^{-1} \mathrm{yr}^{-1}$ ] (see Fig. 4), and $\rho$ is the effective density of posts in the plan area 5 above the aquifer [posts ha ${ }^{-1}$ ].

In Figs. 7 and $1, M_{i}$ and $M_{o}$ are the mass fluxes of arsenic into and out of the aquifer slab;

$M_{i}=v \Theta c_{i} D L_{2} ; M_{o}=\Theta c_{o} D L_{2}$

where $c_{i}$ and $c_{o}\left[\mu \mathrm{g}-\mathrm{As} \mathrm{L}^{-1}\right]$ are the concentrations of arsenic in the groundwater entering and exiting the system. Since $M_{i}+T=M_{o}$, the concentration of As in the groundwater leaving the slab system, if none is entering and the aquifer is well-mixed, will be,

$c_{o}=\frac{1}{3650} \frac{m \rho L_{1}}{v D \Theta}$

For an prismoidal-shaped aquifer, there would only be loading via the triangular upper15 that of Eq. (6).

Calculations were carried out using Eq. (6), to predict the As concentration of water leaving the major aquifer of the plains, the prism-shaped Wairau system (Woodbourne soil series) (Fig. 8), as well as the rectangular Brancott (Spring Creek soils), and Rarangi (Rarangi soils) shallow aquifer systems. As noted already, the Wairau system meets an aquiclude at Hammerich's Road, halfway down the valley. Beyond here, most of the groundwater rises to enter surface streams. The Rarangi shallow aquifer feeds springs under the sea in Cloudy Bay. Whereas the density of posts within a vineyard is $580 \mathrm{ha}^{-1}$, we take the spatially averaged value across the whole surface 25 land-area to be three-quarters of this: so in Eq. (4), $\rho=435 \mathrm{ha}^{-1}$. The location of the 15000 ha of vineyards can be seen in red in Fig. 8 .
HESSD

3, 2037-2061, 2006

CCA leaching from treated timber posts

B. E. Clothier et al.

Title Page

Abstract

Introduction

Conclusions

References

Tables

Figures

14

$>1$

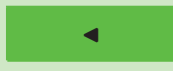

Back

Close

Full Screen / Esc

Printer-friendly Version

Interactive Discussion 
Water moves rapidly $\left(v=30 \mathrm{~m} \mathrm{~d}^{-1}\right)$ along the long axis $\left(L_{1}=15 \mathrm{~km}\right)$ of the Wairau aquifer system, so that despite the steady-state loading of $m=72 \mathrm{mg}-\mathrm{Aspost}^{-1} \mathrm{yr}^{-1}$, the long-term exit concentration, where the water rises to the surface on the aquiclude, would be just $c_{o}=0.5 \mu \mathrm{g}-\mathrm{As} \mathrm{L}^{-1}$. The long-term spatially averaged concentration of 5 arsenic in the leachate under a vineyard would be a steady $12.5 \mu \mathrm{g}$-As $\mathrm{L}^{-1}$ (Fig. 6). However, the dilution provided by the aquifer system means that the groundwater entering surface bodies at Hammerich's Road has a level of arsenic just one twentieth the NZDWS. Likewise, for the rectangular Rarangi shallow aquifer system, the high velocity of flow $\left(v=10 \mathrm{~m} \mathrm{~d}^{-1}\right)$ results in a dilution to achieve an exit concentration just $0.7 \mathrm{ppb}$ of 10 arsenic.

The southern valley aquifer systems, of which the Brancott aquifer is one example, are sluggish, with just $v=1 \mathrm{~m} \mathrm{~d}^{-1}$. Furthermore, these aquifers are not formed from uniform gravels, rather they tend to be non-uniformly distributed throughout the envelope of the surrounding matrix. The overall porosity is now estimated to be just $\Theta \approx 0.1$.

In this case then, the aquifer system cannot provide sufficient dilution of the arsenic leaching from above, and the long-term exit concentration is predicted to be $13 \mathrm{ppb}$. The Marlborough District Council now seeks further investigation of the southern-valley aquifers.

\section{Conclusions}

20 Measurements of arsenic leaching from $\mathrm{H} 4$-treated posts indicate a release rate into the soil of around 5-6 mg-As month ${ }^{-1}$ post $^{-1}$. Using a mechanistic model running on a daily time-step, we have predicted the local pattern dynamics of arsenic transport and fate around the post over a period of 30 years. The rise in the arsenic concentration in the soil, and the pattern of arsenic flux in the soil solution is controlled by the "chemistry" of the Marlborough region, the level of arsenic close to the post is predicted to rise, over

HESSD

3, 2037-2061, 2006

CCA leaching from treated timber posts

B. E. Clothier et al.

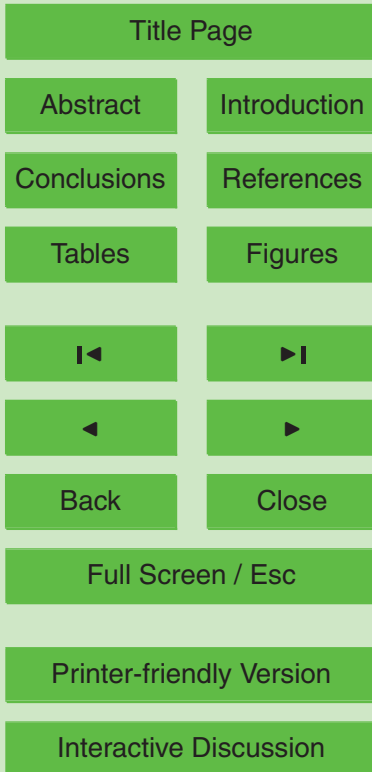

EGU 


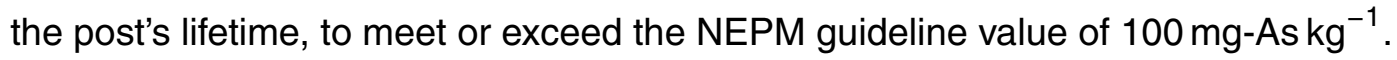

Sustainability is about the long-term, and concerns have been raised about the eventual impact of the use of CCA-treated posts for which there is a $5 \%$ annual replacement rate. On average, therefore, any given post is replaced every 20 years. Our modelling 5 over 500 years, under a replacement regime, revealed that the spatially averaged arsenic concentration leaching through the soil underneath a vineyard would eventually reach a steady-state value. This value, some 1.25 to 1.7 times the drinking water standard, was not strongly affected by the soil's chemical characteristics, although the time taken to reach the steady value was. The steady concentration was primarily determined by the release rate of As from the post over its lifetime, and the physics of the flow.

Finally, we developed a simple hydrogeological model of an aquifer, which we could apply to the major subterranean systems of Marlborough. This mass-balance model predicts the concentration of arsenic at the distal interface of an aquifer receiving a steady loading of arsenic plumes from above. For the major Marlborough aquifer system, the Wairau, the high velocity of flow $\left(30 \mathrm{~m} \mathrm{~d}^{-1}\right)$ through this deep $(20 \mathrm{~m})$ aquifer results in dilution of the received arsenic to one twentieth of the drinking water standard. However for the sluggish and distributed aquifers in the southern valleys, the flow appears incapable of diluting the leachate. It is predicted that the water leaving these aquifers would be around 1.3 times the drinking water standard.

Using our mechanistic modelling tool, SPASMO, we have been able to determine key characteristics of the pattern dynamics of arsenic flow locally around H4-treated posts. Furthermore, we have been able to use this approach to upscale our results, both in time and space, so that we could assess the long-term risks at the vineyard and 25 regional scale.

Acknowledgements. Funding for these research projects was provided by the Marlborough District Council and the Marlborough Research Centre Trust.

\section{HESSD}

3, 2037-2061, 2006

CCA leaching from treated timber posts

B. E. Clothier et al.

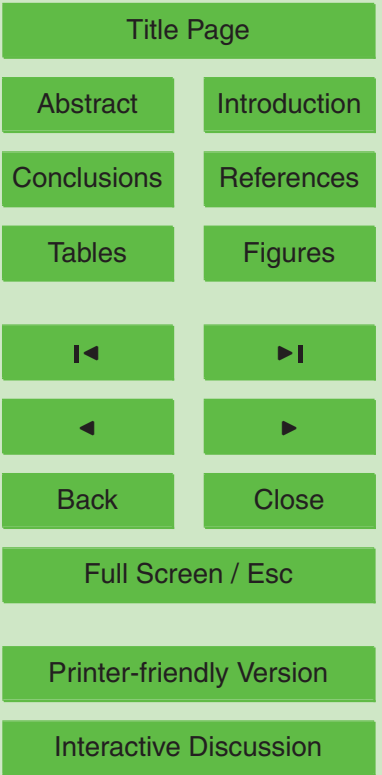




\section{References}

Allen, R. G., Pereira, L. S., Raes, D., and Smith, M.: Crop evapotranspiration. Guidelines for computing crop water requirements, FAO Irrigation and Drainage Paper No. 56, FAO, Rome, 301 pp., 1999.

5 Álvarez-Benedi, J., Bolado, S., Cancillo, I., Calvo, C., and García-Sinovas, D. Adsorptiondesorption of arsenate in three Spanish soils, Vadose Zone J., 4, 282-290, 2005.

Brookes, K. M.: A critical review of Townsend et al. (2001) "Leaching and toxicity of CCA-treated and alternative treated wood products, Aquat. Environ. Sci., Port Townsend, Washington, USA, 23pp., 2005.

Bourne R.: Post-mortem: Research spotlight falls on treated timber, Horticulture News, August edition, 21-24. 2003.

Goldberg, S., Lesch, S. M., Suarez, D. L., and Basta, N. T.: Predicting arsenate adsorption by soils using soil chemical parameters in the constant capacitance model, Soil Sci. Soc. J., 69, 1389-1398, 2005.

15

Green, S. R., Vogeler, I., Clothier, B. E., Mills, T. M., and van den Dijssel, C.: Modelling water uptake by a mature apple tree, Australian J. Soil Res., 41, 365-380, 2002.

Hutson, J. L. and Wagenet, R. J.: A pragmatic field-scale approach for modelling pesticides, J. Environ. Qual., 22, 494-499, 1993.

Islam, A., Karim, A. J. M. S., Khaled, H. M., Mitra, B. K., and Miah, M. A. M.: Arsenic sorption characteristics of four agricultural soils of Bangladesh, Asian J. Plant Sci., 2, 1149-1152, 2003.

Jin, L. and Archer, K.: Copper based wood preservatives: observations on fixation, distribution and performance, Proc. Annu. Meet. Am. Wood Preserv. Assoc., Woodstock, Md.: The Association, 87, 169-184, 1991.

Ministry of Health Drinking water standards for New Zealand, New Zealand MoH, Wellington, (http://www.ephc.govt.au).

National Environmental Protection Measures, Guidelines on the Investigation Levels for Soil and Groundwater Schedule B(1), Environmental Protection and Heritage Council, (http:// www.moh.govt.nz), 1999.

30 Robinson, B. H., Greven, M. M., Green, S. R., Sivakumaran, S., Davidson, P., and Clothier, B. E.: Leaching of copper, chromium and arsenic from treated timber vineyard posts in Marlborough, New Zealand, Sci. Total Environ., 364, 113-123, 2006.

\section{HESSD}

3, 2037-2061, 2006

CCA leaching from treated timber posts

B. E. Clothier et al.

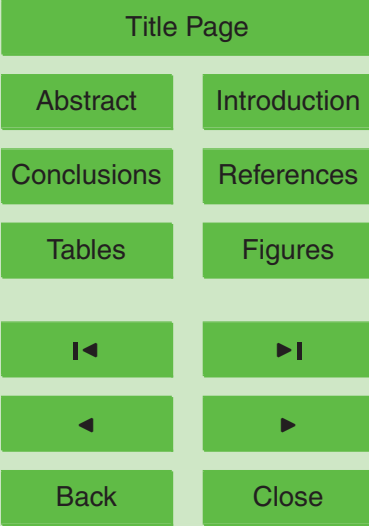

Full Screen / Esc

Printer-friendly Version

Interactive Discussion 
Rosen, M. R., Reeves, R. R., Green, S. R., Clothier, B. E., and Ironside, N.: Prediction of groundwater nitrate contamination after closure of an unlined sheep feedlot in New Zealand, Vadose Zone J., 3, 990-1006, 2004.

Smith, E., Naidu, R., and Alston, A. M.: Chemistry of inorganic arsenic in soils: II Effect of phosphorus, sodium and calcium on arsenic sorption, J. Environ. Qual., 31, 557-563, 2002.

Vogeler, I., Green, S. R., Greven, M. M., Robinson, B. H., van den Dijssel, C. W., and Clothier, B. E.: Environmental risk assessment of CCA leaching from treated vineyard posts, HortResearch Client Report No. 17659, 44pp, 2005.

\section{HESSD}

3, 2037-2061, 2006

CCA leaching from treated timber posts

B. E. Clothier et al.

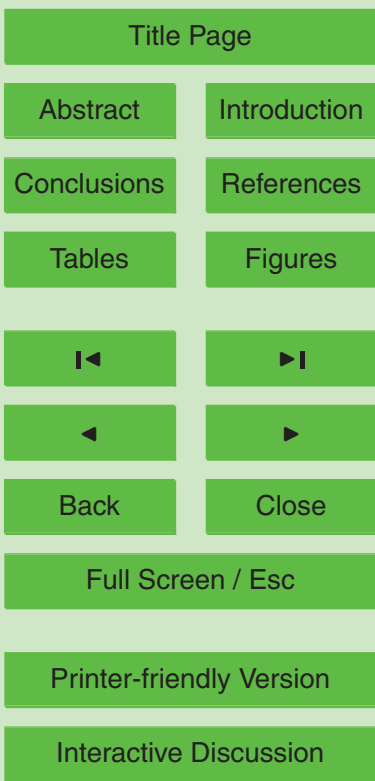




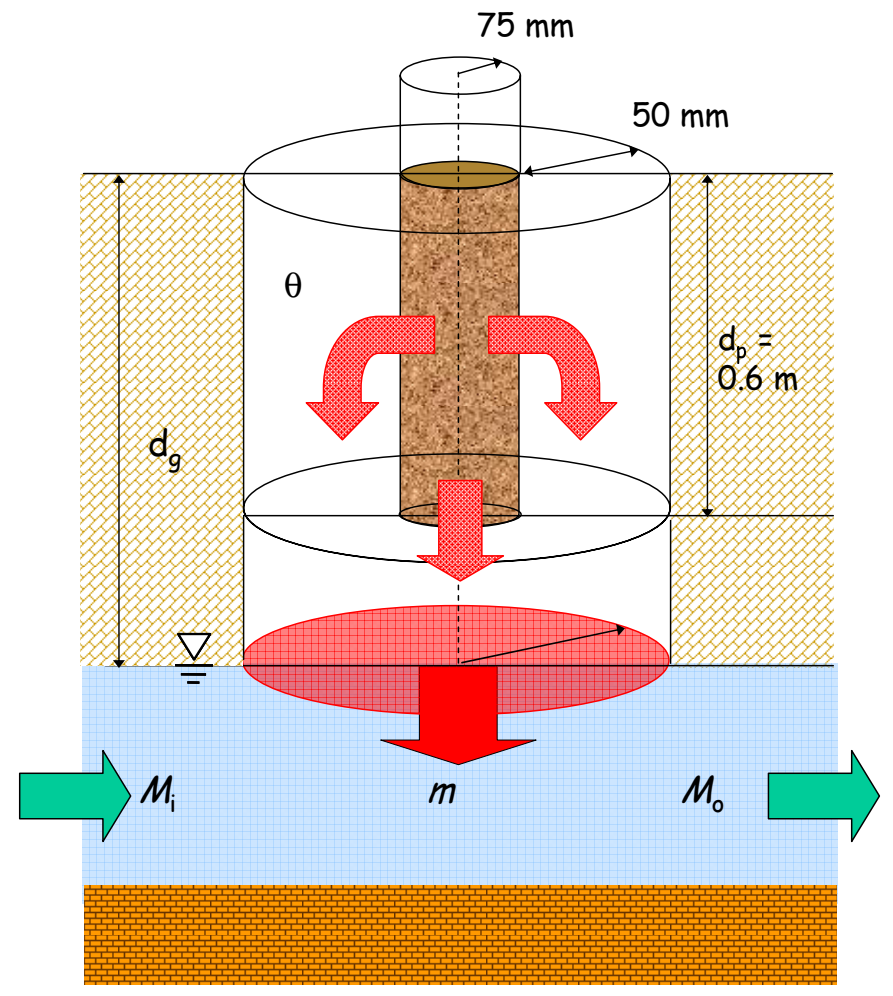

Fig. 1. The CCA leaching processes described in the SPASMO model. Here $d_{g}$ is the depth to groundwater, $\theta$ is the soil water content, $m$ [mg-As post ${ }^{-1}$ month $^{-1}$ ] is the flux of As leaving the post, and $M_{i}$ and $M_{o}$ [mg-As $\mathrm{yr}^{-1}$ ] are the arsenic fluxes into and out of the groundwater upstream and downstream of the posts.

\section{HESSD}

3, 2037-2061, 2006

CCA leaching from treated timber posts

B. E. Clothier et al.

Title Page

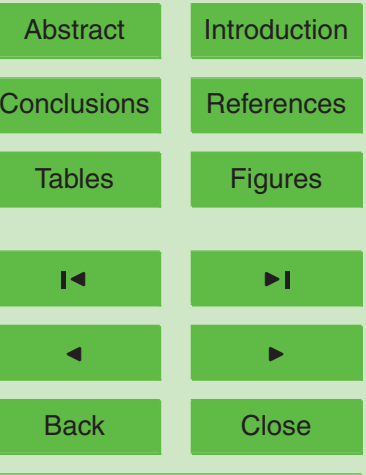

Full Screen / Esc

Printer-friendly Version

Interactive Discussion 


\section{HESSD}

3, 2037-2061, 2006

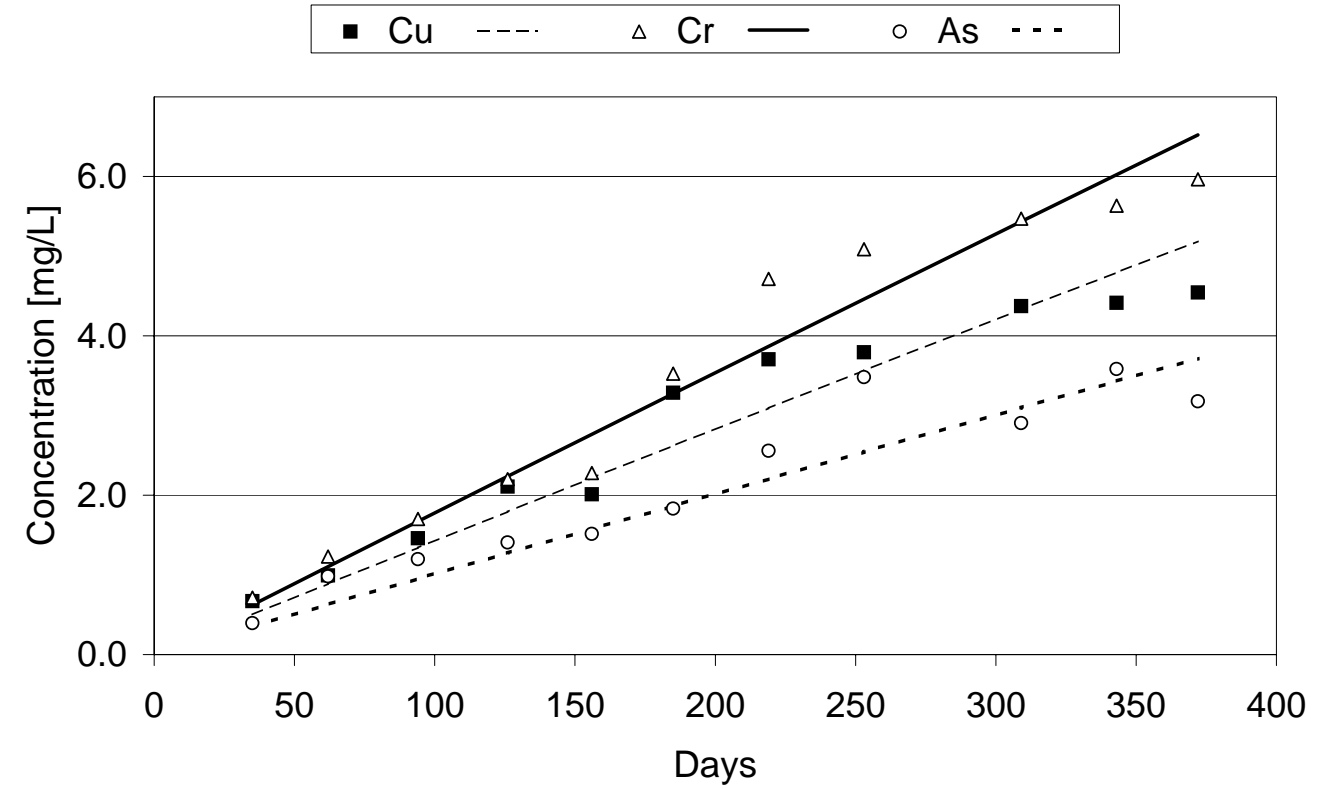

CCA leaching from treated timber posts

B. E. Clothier et al.

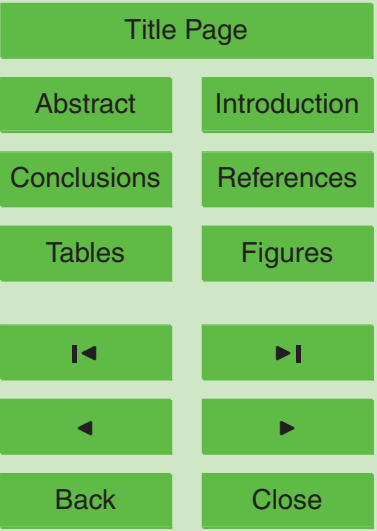

Full Screen / Esc

Fig. 2. Release of copper, chromium and arsenic from full-round posts submerged in a $50 \mathrm{~L}$ container of water. The fits of the first-order formulae are shown (Eq. 3).

Printer-friendly Version

Interactive Discussion 


\section{HESSD}

3, 2037-2061, 2006

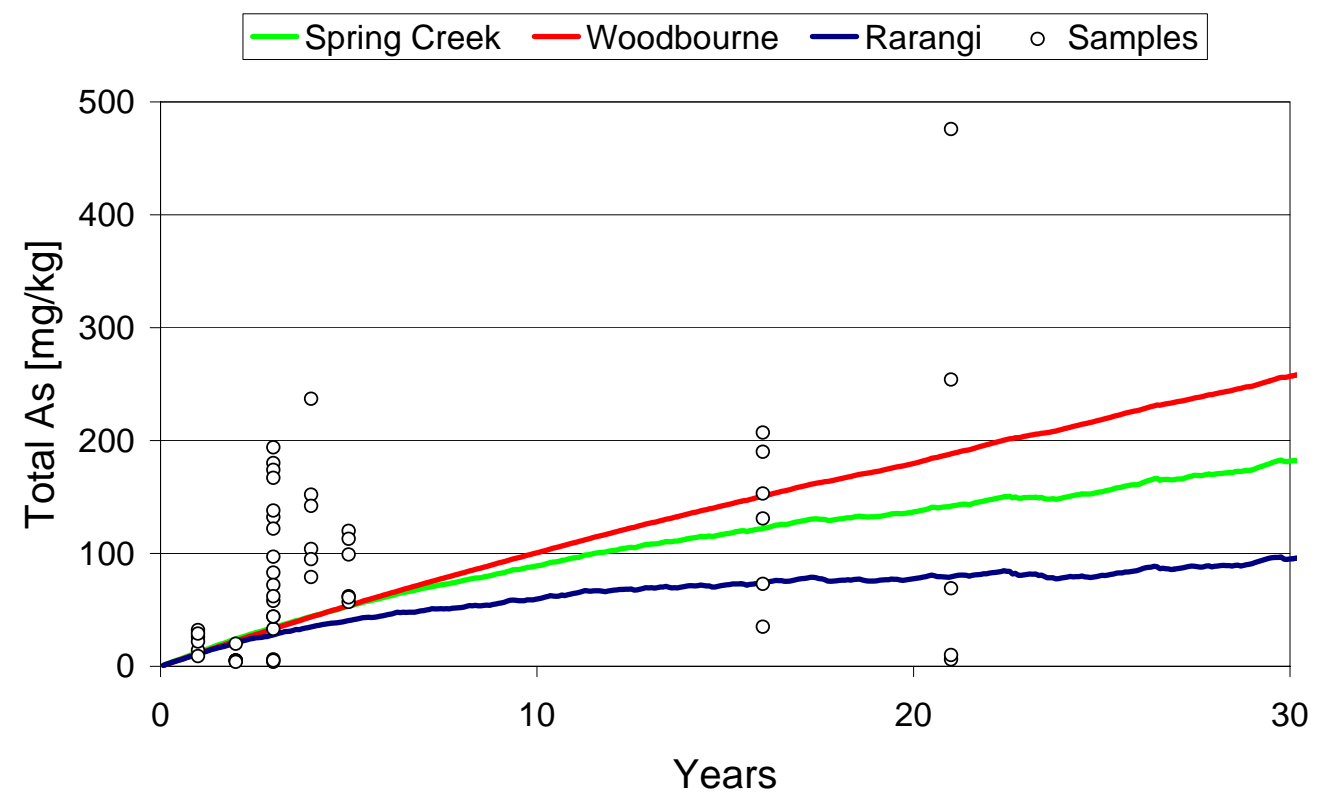

CCA leaching from treated timber posts

B. E. Clothier et al.

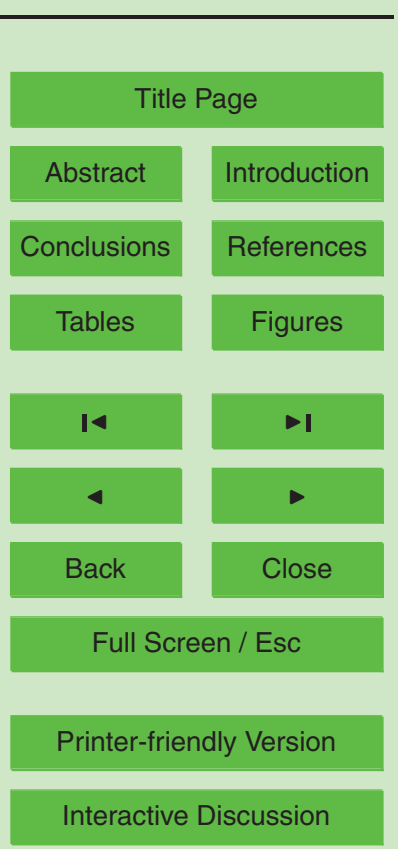

EGU

Fig. 3. The effect of soil type on soil arsenic concentration immediately under the post predicted by SPASMO modelling (lines). The symbols represent samples collected within $50 \mathrm{~mm}$ of posts of various ages on a range of Marlborough soils (Robinson et al., 2006). The pattern dynamics are a reflection of the ability of the soil to exchange and "hold" arsenic.

Interactive Discussion 


\section{HESSD}

3, 2037-2061, 2006

CCA leaching from treated timber posts

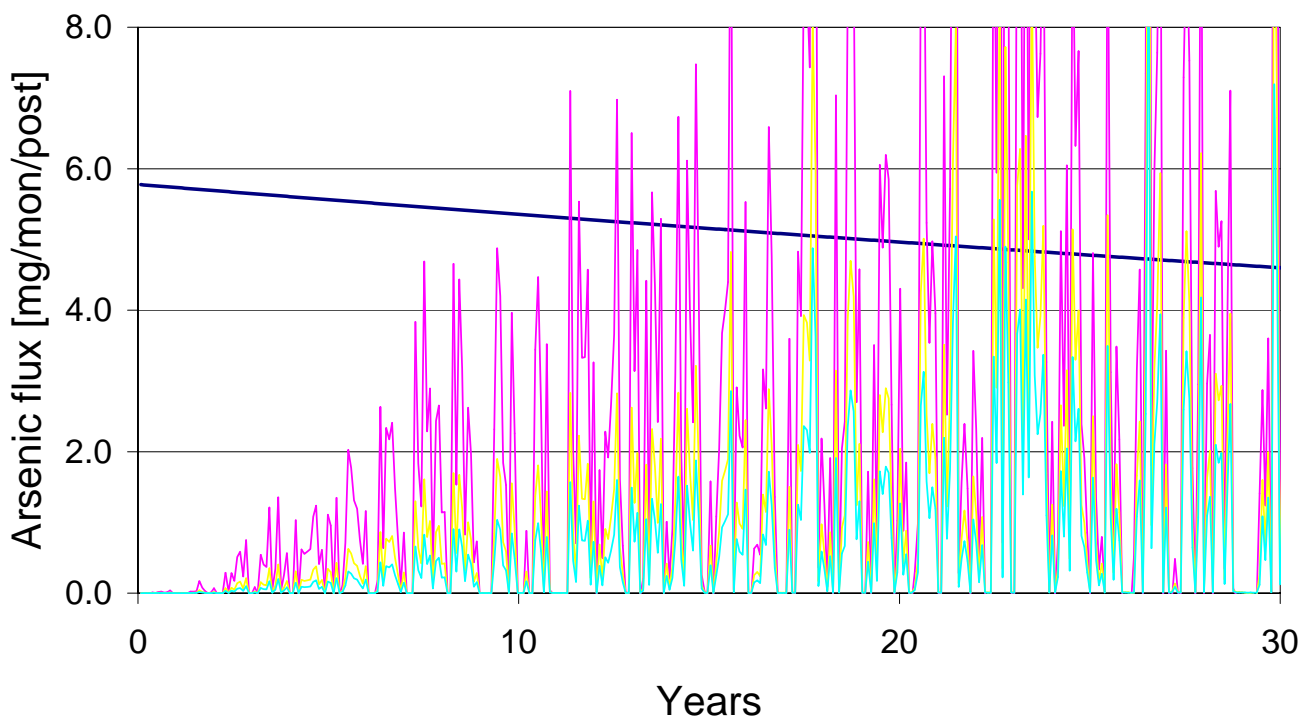

B. E. Clothier et al.

Title Page
Abstract

Conclusions

Tables

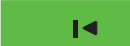

4

4

Back
Introduction

References

Figures

I

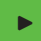

Close
Fig. 4. Predictions of the flux of arsenic moving down through a cylinder $(r=125 \mathrm{~mm})$ surrounding a post in the light-textured Rarangi soil. The flux, $m$, through a circular plane (Fig. 1 ) is given for the depths of 1,2 and $3 \mathrm{~m}$. Also given is the flux of arsenic being released through the subterranean surfaces of the post into the soil.

\section{Full Screen / Esc}

Printer-friendly Version

Interactive Discussion 


\section{HESSD}

3, 2037-2061, 2006

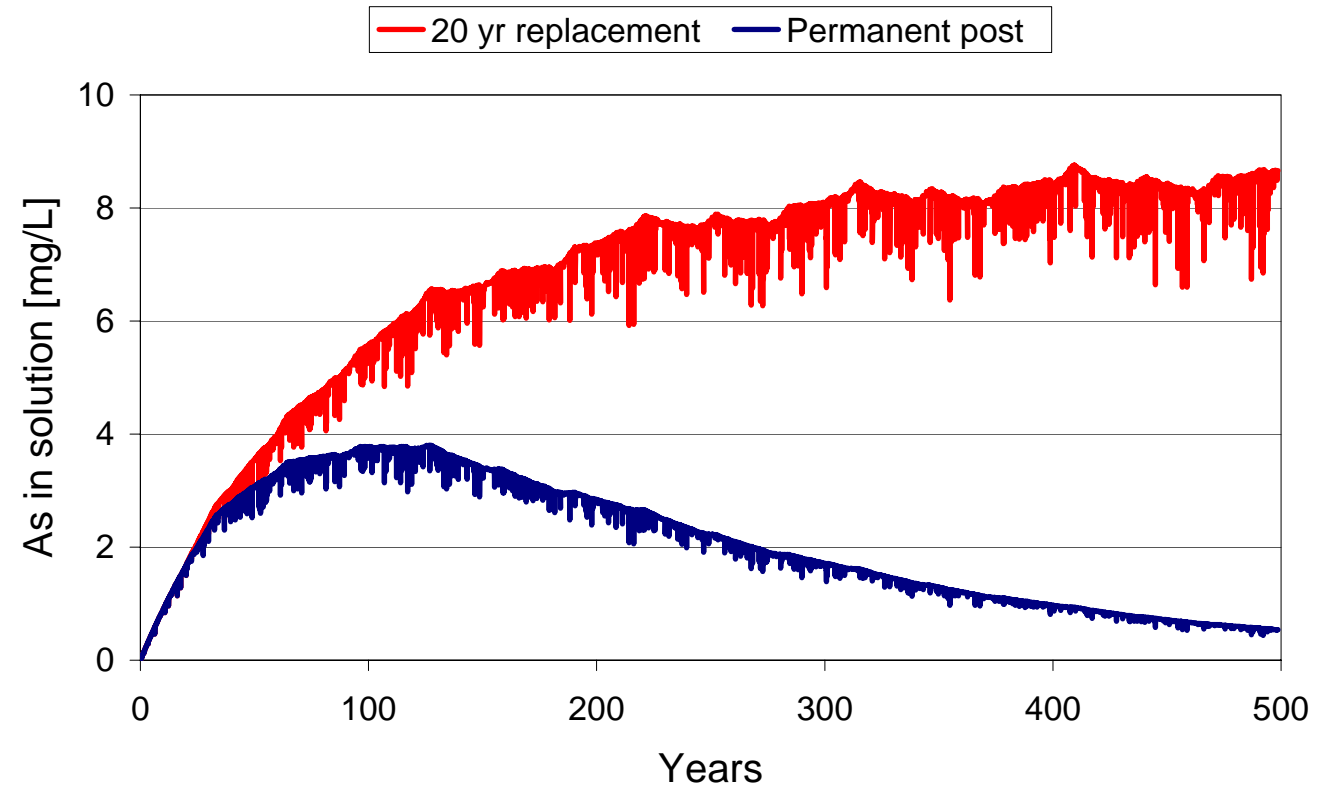

Fig. 5. The predicted concentration of arsenic in the soil solution close to, and alongside a post in the heavier Woodbourne soil. The lower line is for a single post that remains in the soil during the whole of the 500-year simulation period, whereas the upper line is for the case where every 20 years the post is removed, and a "fresh" replacement is inserted into the same hole.
CCA leaching from treated timber posts

B. E. Clothier et al.

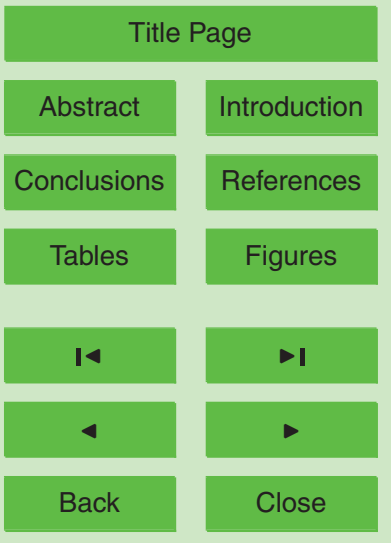

Full Screen / Esc

Printer-friendly Version

Interactive Discussion 


\section{HESSD}

3, 2037-2061, 2006
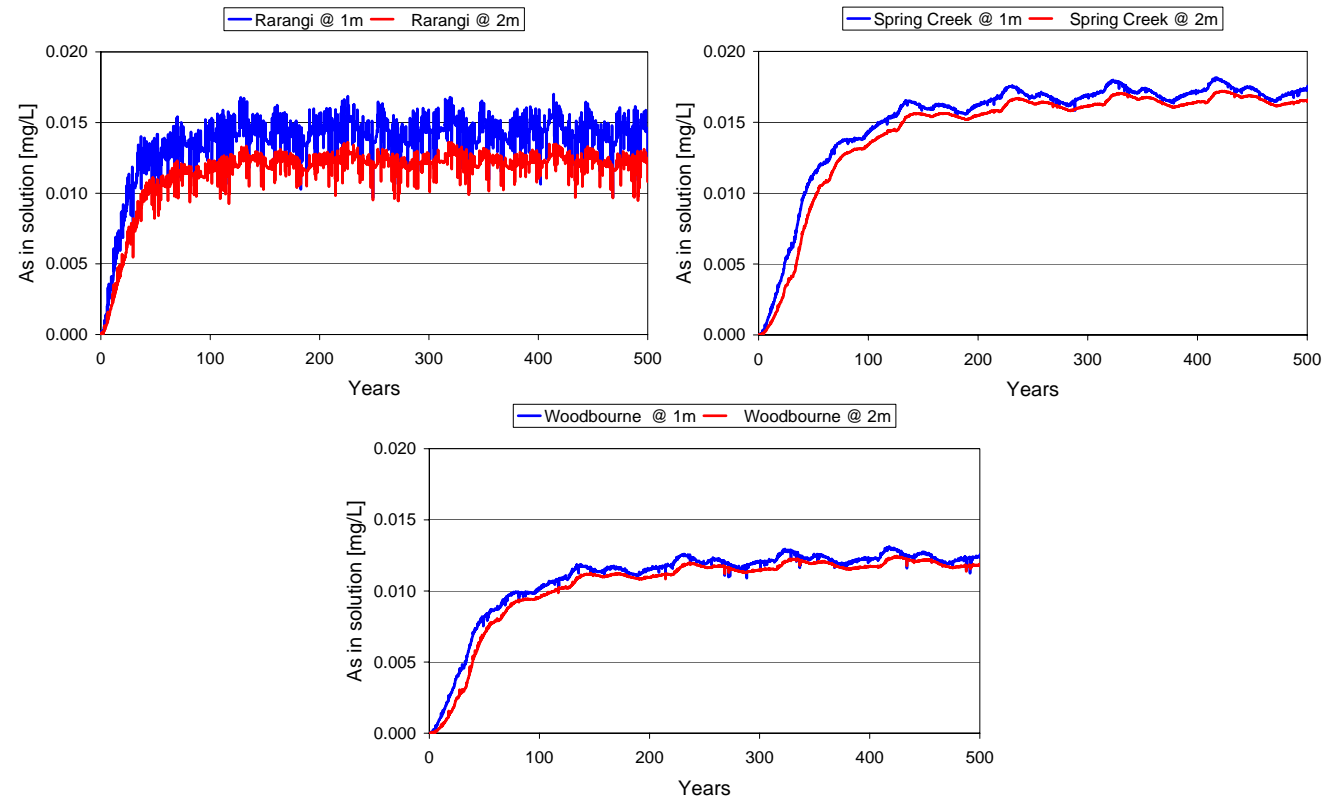

Fig. 6. Five-hundred year simulations of the spatially averaged solution concentration of arsenic, at depths of 1 and $2 \mathrm{~m}$, under a field of posts at density $580 \mathrm{ha}^{-1}$ (Rarangi at top left, Spring Creek at top right, and Woodbourne at bottom). The life-time of a post was taken to be 20 years, and there was then replacement with a "fresh" post.
CCA leaching from treated timber posts

B. E. Clothier et al.

Title Page

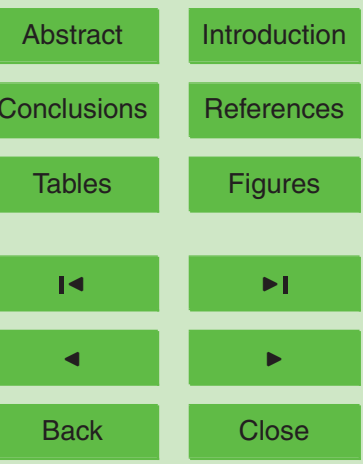

Full Screen / Esc

Printer-friendly Version

Interactive Discussion 


\section{HESSD}

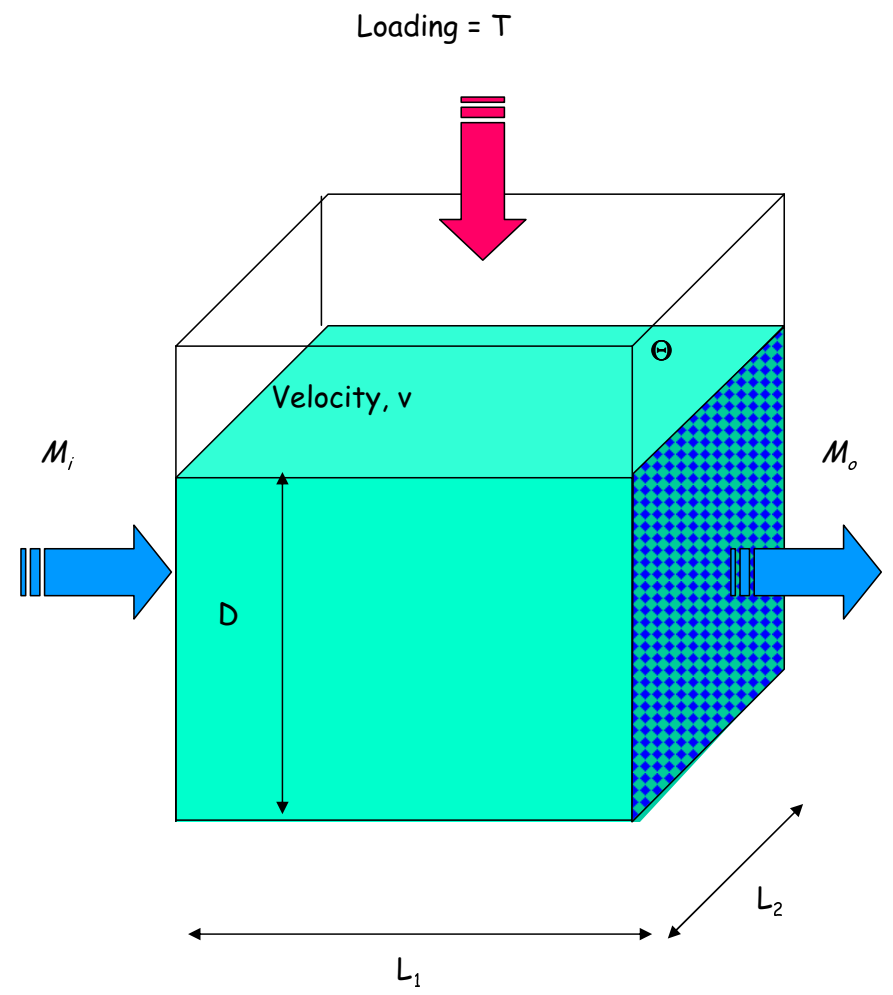

3, 2037-2061, 2006

CCA leaching from treated timber posts

B. E. Clothier et al.

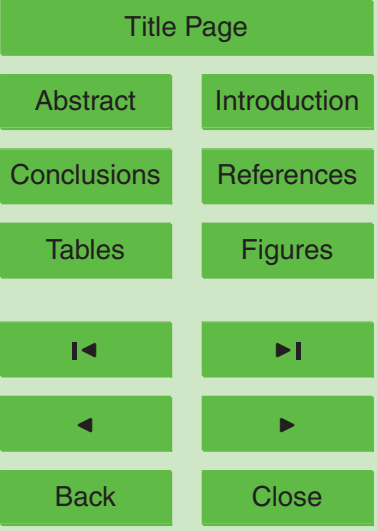

Full Screen / Esc

Printer-friendly Version

Interactive Discussion
Fig. 7. A simple hydrogeological model of a rectangular aquifer system through which groundwater is travelling at pore velocity $v$, and which is receiving an arsenic loading of $T$ via leachate from the surface above.

\section{EGU}




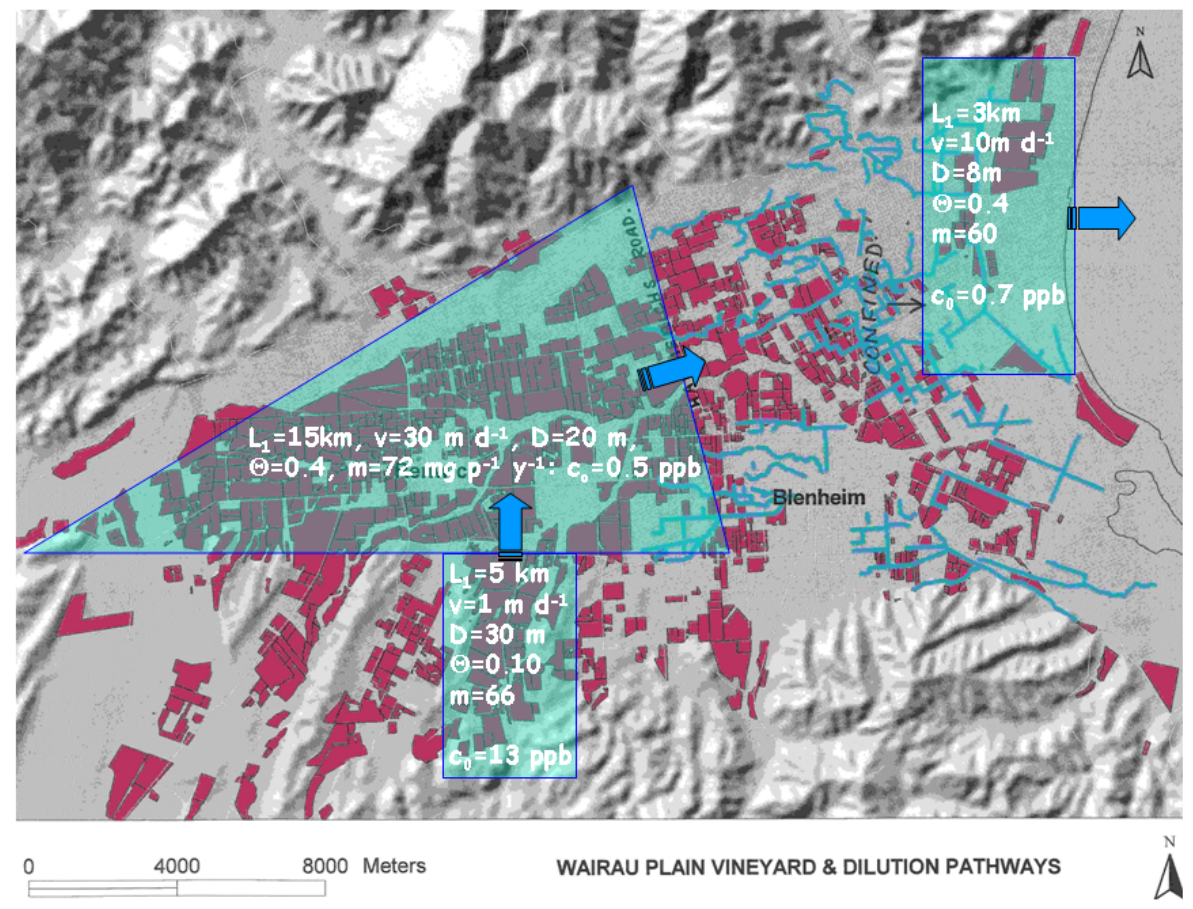

Fig. 8. A map of the Wairau Valley of Marlborough, New Zealand, showing the location of vineyards (red). Superimposed on the map are our simple geometrical models for the triangular Wairau aquifer system (centre left), the Rarangi shallow aquifer system (top right), and the Brancott aquifer system (lower centre). The parameters used in our simple hydrogeological model to predict $c_{o}$ (Eq. 6) are shown.

\section{HESSD}

3, 2037-2061, 2006

CCA leaching from treated timber posts

B. E. Clothier et al.

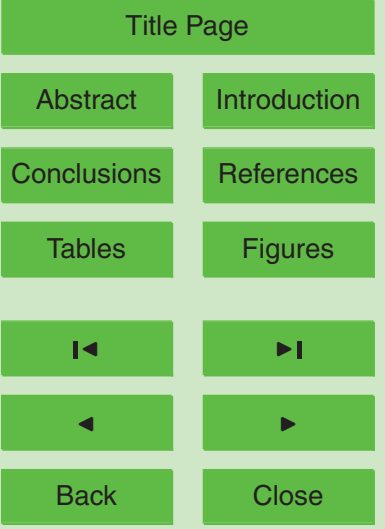

Full Screen / Esc

Printer-friendly Version

Interactive Discussion 